\title{
Stabilization of multiple heavy metal contaminated soils using discarded crab shell
}

\author{
Yijian Feng ${ }^{l}$, Zhong Zhong ${ }^{l}$, and Chi Zhang ${ }^{l^{*}}$ \\ ${ }^{1}$ Zhejiang Environmental Science \& Design institute, Hangzhou, Zhejiang, 310007, China
}

\begin{abstract}
Stabilizing heavy metal contaminated soil is a popular remediation model in China. Many waste biomass materials have been proven to have a stabilizing effect on heavy metals but also have several advantages like environmental friendliness and waste utilization. In this study, the waste crab shells were selected as raw materials for stabilizing agents, and the stabilization effects on different heavy metals after incineration and pyrolysis treatment was explored. The obvious stabilizing effect of pyrolytic crab shell powder on $\mathrm{Cr}$ and $\mathrm{Cr}^{6+}$ was observed, and the excellent stabilizing effect of the incinerated crab shell powder on $\mathrm{Cu}, \mathrm{Zn}, \mathrm{Pb}, \mathrm{Ni}$ was also confirmed. After mixing the two crab shells, the overall stabilization effect of $\mathrm{Cr}$ and $\mathrm{Cr}^{6+}, \mathrm{Cu}, \mathrm{Zn}, \mathrm{Pb}, \mathrm{Ni}$ and other heavy metals can reach the desired level (The stabilization efficiency of $\mathrm{Cr}, \mathrm{Cr}^{6+}, \mathrm{Cu}, \mathrm{Zn}, \mathrm{Pb}, \mathrm{Ni}$ was $89.0 \%, 89.1 \%, 93.3 \%, 86.1 \%$ and $96.1 \%$,respectively).
\end{abstract}

\section{Introduction}

Heavy metals (HMs) pollution is a common problem for the retired industrial sites such as electroplating, metal smelting, lead battery manufacturing and dye preparation, in China[1-4].These HMs "brownfields" are caused by the poor production activity management in the past decades. Among the HMs pollutants, $\mathrm{Cu}, \mathrm{Zn}, \mathrm{Pb}, \mathrm{Ni}, \mathrm{Cr}$ and $\mathrm{Cr}^{6+}$ are very common according to previous papers [5-7] and our experience.

In order to eliminate or reduce soil HMs pollution problems, technologies such as excavation \& landfill, washing, stabilization and phytoremediation have been developed and applied in the past or present. However, with China's stricter environmental management requirements for landfill areas, excavation \& landfill is no longer applicable; The washing process is not suitable for HMs contaminated soils with high clay proportions according to research [8-9] and practice results; As for phytoremediation, problems such as long repair cycle requirement, fate of plants, and poor repair effect on high-contamination contaminated soil were also exposed in actual remediation. In contrast, soil stabilization appears to be more applicable at this stage especially for large-scale remediation due to its relatively short remediation time and lower cost. The stabilization of HMs contaminated soil is aim to reduce HMs mobility in soil through chemical reaction, physical adsorption by adding immobilizing additives[10-13]. Various types of additives such as phosphorus, lime, clay has been chosen as stabilizer. These substances contain chemical reagents and mineral materials with a certain proportion. In fact, with the broadening of the research horizon, some waste biomass has also been included in the research scope as a new type of stabilizing agent, such as modified waste straw, waste corn straw, sludge, animal bones, shell, etc.. Compared with chemical agents, biomass stabilizers not only make full use of waste, reduce the negative impact of waste biomass on the environment, but also have a certain positive effect on the increase of some beneficial components in the soil.

In view of these advantages of waste biomass, it is of great practical significance to carry out research on the preparation of stabilizing agents by waste biomass for HMs contaminated soil. In many coastal cities with developed industrial economies in China, abandoned crab shells are a considerable amount of biomass. At the same time, the waste crab shell contains calcium carbonate, calcium phosphate, chitin and other ingredients, which theoretically has a certain possibility of stabilizing HMs. This article studied the HMs stabilization effect of another type of waste biomass, i.e. waste crab shells. In this paper, $\mathrm{Cu}, \mathrm{Zn}, \mathrm{Pb}, \mathrm{Ni}, \mathrm{Cr}$ and $\mathrm{Cr}^{6+}$ was chosen as typical HMs pollutants for HMs compound polluted sites and the effects of crab shell was discussed.

\section{Materials and methods}

\subsection{Materials}

Lead nitrate $\left(\mathrm{Pb}\left(\mathrm{NO}_{3}\right)_{2}, 98 \%\right.$ purity), Copper nitrate $\left(\mathrm{Cu}\left(\mathrm{NO}_{3}\right)_{2}, 98 \%\right.$ purity), Zinc sulfate $\left(\mathrm{ZnSO}_{4}, 98 \%\right.$ purity), Nickel chloride ( $\mathrm{NiCl}_{2}, 98 \%$ purity), Potassium chromate $\left(\mathrm{K}_{2} \mathrm{CrO}_{4}\right)$ and Chromium sulfate $\left(\mathrm{Cr}_{2}\left(\mathrm{SO}_{4}\right)_{3}\right.$, 98\%) were used for the preparation of mixed solutions of HMs. 
Contaminated soil was simulated by adding the HMs mixed solution into clean yellow-brown loam. Firstly, the dried soils were sieved through a $1 \mathrm{~mm}$ mesh sieve to remove large stones and plant roots prior to use. Then, the mixed solution of $\mathrm{Pb}\left(\mathrm{NO}_{3}\right)_{2}, \mathrm{Cu}\left(\mathrm{NO}_{3}\right)_{2}, \mathrm{ZnSO}_{4}, \mathrm{NiCl}_{2}$, $\mathrm{K}_{2} \mathrm{CrO}_{4}, \mathrm{Cr}_{2}\left(\mathrm{SO}_{4}\right)_{3}$ was added into the soil. After thorough mixing and sifting for several times, the soil was dried in the sun for 30 days. Finally, the analytical results showed that $844 \mathrm{mg} \mathrm{kg}^{-1} \mathrm{~Pb}, 4530 \mathrm{mg} \mathrm{kg}^{-1} \mathrm{Cu}, 4260 \mathrm{mg} \mathrm{kg}^{-1} \mathrm{Zn}$, $305 \mathrm{mg} \mathrm{kg}^{-1} \mathrm{Ni}$, Cr $327 \mathrm{mg} \mathrm{kg}^{-1}$ and $\mathrm{Cr}^{6+} 94.5 \mathrm{mg} \mathrm{kg}^{-1}$ contained in soil. The concentration of these HMs was basically close to the actual case of electroplated contaminated cases in China.

Abandoned crab shells were collected from a seafood processing plant. After days of natural air dry, the dried crab shells were crushed into powder (less than $0.5 \mathrm{~mm}$ ). Part of crab shells powder (abbreviated as CSP) was used for pyrolysis under $400^{\circ} \mathrm{C}$ for $30 \mathrm{~min}$ in a muffle furnace. This part of CSP was called as CSP-P for short. At the same time, another part of CSP was baked under $990^{\circ} \mathrm{C}$ for 30min as in a muffle furnace. This baked part of CSP was abbreviated as CSP-B in this paper.

With the aim of compare the stabilization effect, we also added comparison groups such as straw biochar (straw powder pyrolysis under $400^{\circ} \mathrm{C}$ for $30 \mathrm{~min}$, abbreviated as St-char), baked ox bone powder (baked under $990^{\circ} \mathrm{C}$ for $30 \mathrm{~min}$, abbreviated as OBP-B), shell powder (baked under $990^{\circ} \mathrm{C}$ for $30 \mathrm{~min}$, abbreviated as SP-B), and baked eggshell powder (roasted under $990^{\circ} \mathrm{C}$ for $30 \mathrm{~min}$, abbreviated as ESP-B).

\subsection{Method}

Prepared contaminated soil was stabilized by the addition of only SP-b, ESP-B, OPB-B, CSP-B, CSP-P, CSP or St-char at the ratio of $2 \%$. Distilled water was added into each group for moisture adjust (Thoroughly mix soil with additives during watering). After this step, each group was covered by PE membrane and cured for $5 \mathrm{~d}$. These stabilized soil were performed Leaching Toxicity-Horizontal vibration method (HJ 557-2010) to determine the mobility of HMs present in soil samples. HMs leaching steps are as follows: 100g of stabilized soil (dry weight) each group were taken for tests in separate PE bottles (2L). According to the liquid-solid (dry weight) ratio of 10: 1, the corresponding amount of distilled water was added, followed by vibration process (The vibration frequency was controlled at 110 times/min with vibration amplitude was controlled at $40 \mathrm{~mm}$ for $8 \mathrm{~h}$ ). All extractions were filtered using a $0.45 \mu \mathrm{m}$ micro-filtration membrane. $\mathrm{Pb}, \mathrm{Cu}, \mathrm{Zn}$ and $\mathrm{Ni}$ concentrations in the extractions $\mathrm{Cu}, \mathrm{Zn}$, $\mathrm{Pb}, \mathrm{Ni}, \mathrm{Cr}$ and $\mathrm{Cr}^{6+}$ were analyzed by atomic absorption spectrometry (Shimadzu AA-6300C following EPA method 7000B). All of these were carried out in triplicate. In order to study the effect of different treatment methods of CSP on the stabilizing effect of HMs, the pyrolysised, baked, untreated CSP groups were set in this paper. In addition, single factor experimental groups such as addition from $2 \% \sim 6 \%$ and curing time of $2 \mathrm{~d}$, $4 \mathrm{~d}$ and $6 \mathrm{~d}$ was also conducted.
To evaluate the stabilization effect, formula (1) was described as followed.

$$
E(\%)=\left(C_{0, x}-C_{i, x}\right) / C_{0, x}
$$

was used $\left(\mathrm{C}_{0, \mathrm{x}}\right.$ represented the leaching concentration of $\mathrm{HM} \mathrm{X}$ without any addition of stabilizer; $\mathrm{C}_{\mathrm{i}, \mathrm{x}}$ represented the leaching concentration of HM X under the addition of stabilizer i).

\section{Results and discussions}

The results (reflected in Fig. 1) showed that under the same dosage ( $2 \%$ ) and curing time (4 days), there were some differences in the effects of stabilizing the HMs of the seven biomass materials. It can be seen that under this experimental condition, CSP-P showed the best stabilization effect on $\mathrm{Cr}(60.99 \%)$, followed by CSP $(57.43 \%)$ and OBP-B (52.25\%).

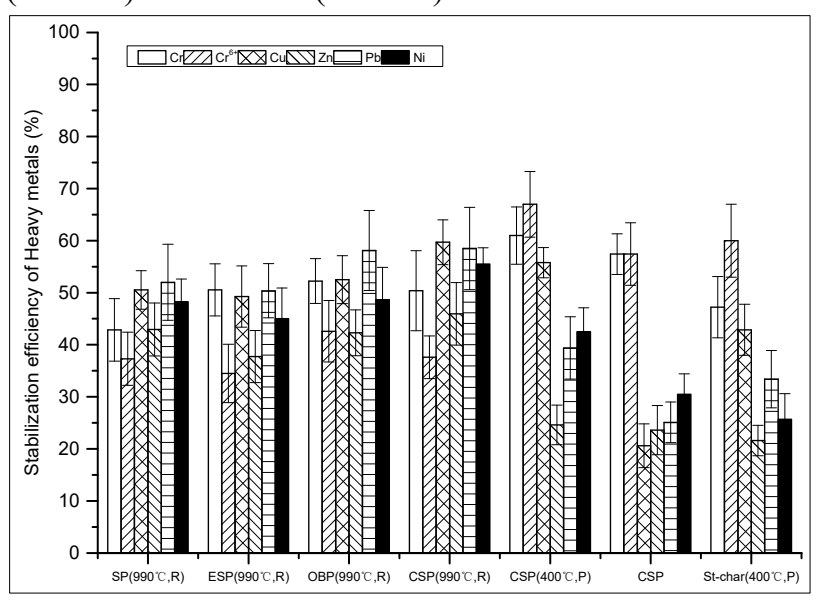

Fig. 1. Stabilization results (2\%, 4days)

For $\mathrm{Cr}^{6+}$ stabilization, the CSP-P group was best immobilized among all these group $(67.02 \%)$, followed by St-char (60.01\%) and CSP (57.09\%). Except for these three substances, the stabilization efficiency of $\mathrm{Cr}^{6+}$ by other agents was basically between $30 \%$ and $40 \%$. This result may be due to the fact that CSP-P and St-char were biochars produced by pyrolysis and had good adsorption of $\mathrm{Cr}^{6+}$. The good stabilizing effect of CSP on $\mathrm{Cr}^{6+}$ was probably because the chitin released from CSP can chelate with $\mathrm{Cr}^{6+}$.

For $\mathrm{Cu}$ stabilization, the CSP-B group was best immobilized among all these group (59.7\%), followed by CSP-P (55.77\%) and OBP-B (52.51\%).

For $\mathrm{Zn}$ stabilization, the CSP-B group was best immobilized among all these group $(45.95 \%)$, followed by SP-B (42.94\%) and OBP-B (42.3\%). In term of $\mathrm{Pb}$ and $\mathrm{Ni}$, the best stabilization also existed in CSP-B (as reflected in Fig. 1.

Therefore, for $\mathrm{Cr}$ and $\mathrm{Cr}^{6+}$, the stabilization effect of pyrolyzed CSP was the best for its good adsorption capacity. For several other $\mathrm{HMs}(\mathrm{Cu}, \mathrm{Zn}, \mathrm{Pb}, \mathrm{Ni})$, the HMs stabilizing effect of crab shells powder baked at high temperature (group CSP-B) was most prominent. The reason may be that the $\mathrm{CaCO}_{3}$ in the crab shell after high-temperature roasting was decomposed into calcium 
oxide and a part of the phosphate included in the crab shell reacted with these HMs to generate hydroxides and phosphates with lower solubility.

On the other hand, it can be seen from Fig.1. that the stability of CSP and CSP after pyrolysis on HMs such as $\mathrm{Cu}, \mathrm{Zn}, \mathrm{Pb}$, Ni was not excellent as they did on $\mathrm{Cr}$ and $\mathrm{Cr}^{6+}$. This may be because the limited amount of chitin in the crab shell may be almost react with $\mathrm{Cr}$ and $\mathrm{Cr}^{6+}$ (few chitin left to react with other HMs); The absorb ability of CSP-P for other HMs was weaker than the chemical stabilization of CSP-B ( $\mathrm{pH}$ of CSP-B was 12.8 and included phosphate, $\mathrm{pH}$ of CSP-P was 8.2). In summary, the stabilization effect of CSP-P and CSP on $\mathrm{Cr}$ and $\mathrm{Cr}^{6+}$ was better than the other biomasses, and the stabilization effect of CSP-B on $\mathrm{Cu}, \mathrm{Zn}, \mathrm{Pb}$, Ni was better than other biomasses. The stabilizing effect of crab shells for HMs has been confirmed.
Therefore, the relationship between the dosage of CSP, CSP-P, and CSP-B, curing time, and stabilization was studied, further (results were shown in Fig. 2 (a). Fig. 2 (i). .

As shown in the CSP group (Fig. 2(a).), the stabilization efficiency of the interest HMs increased with the addition amount of CSP increased. For example, in Fig. 2(a)., stabilization efficiency of $\mathrm{Cr}^{6+}$ has increased from $57.09 \%$ (in the case of $2 \%$ dosing) to $88.36 \%$ (in the case of $6 \%$ dosing); Stabilization efficiency of $\mathrm{Cr}$ has increased from $57.43 \%$ (in the case of $2 \%$ dosing) to $87.80 \%$ (in the case of $6 \%$ dosing); Similar improvements in stabilization efficiency can also be observed in $\mathrm{Cu}, \mathrm{Zn}, \mathrm{Pb}$, Ni. This result may be explained as the increase in the amount of CSP (as reflected in Fig. 2 (a). Fig. 2 (c).) , the chance of chelation between HMs and chitin also increased .

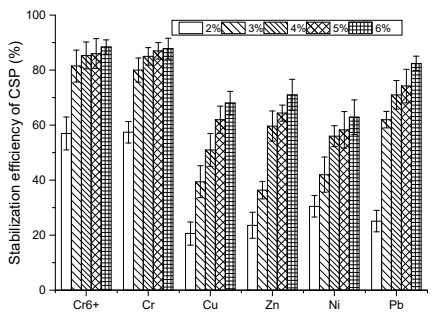

Fig. 2(a). Results of CSP (4 days)

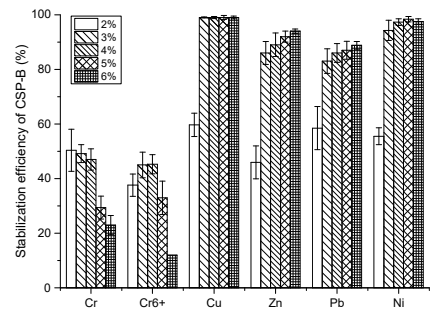

Fig. 2(d). Results of CSP-B (4 days)

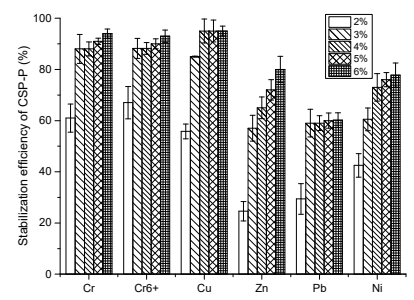

Fig. 2(g). Results of CSP-P (4 days)

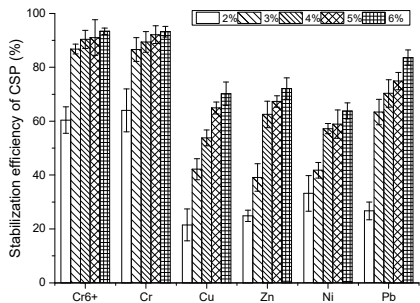

Fig. 2(b). Results (6 days)

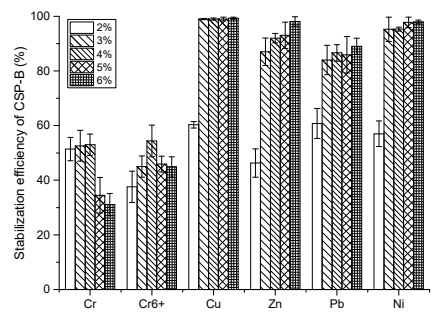

Fig. 2(e). Results of CSP-B (6 days)

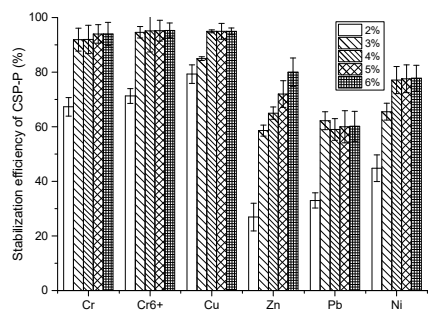

Fig. 2(h). Results of CSP-P (6 days)

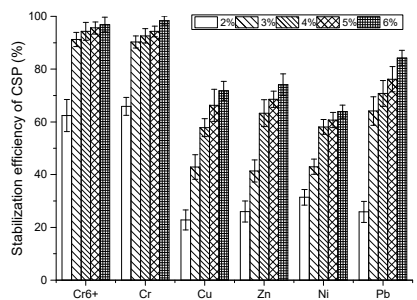

Fig. 2(c). Results of CSP (8 days)

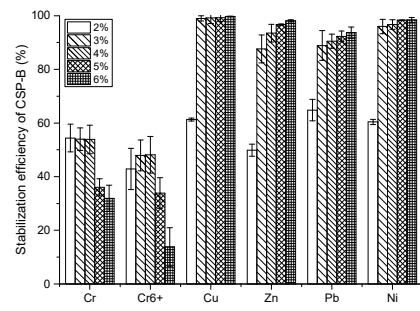

Fig. 2(f). Results of CSP-B (8 days)

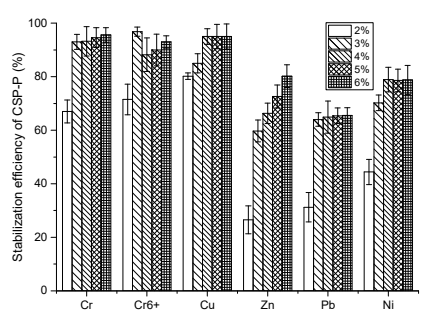

Fig. 2(i). Results of CSP-P (8 days)
In term of CSP-B group (Fig. 2(d) Fig. 2(f)), an interesting phenomenon was discovered. Specifically, with the increase of the amount of CSP-B added, the stabilization efficiency of $\mathrm{Cr}$ and $\mathrm{Cr}^{6+}$ did not increase accordingly (for example, the stabilization efficiency of $\mathrm{Cr}$ decreased; the stabilization efficiency of $\mathrm{Cr}^{6+}$ increased slightly, then a more obvious decline has also occurred). The decrease in the total $\mathrm{Cr}$ stabilization effect may be due to CSP-B input increasing (with alkalinity increased). According to the characteristic of $\mathrm{Cr}, \mathrm{Cr}^{3+}$ is easily oxidized to $\mathrm{Cr}^{6+}$ under alkaline conditions, which eventually leads to an increase in $\mathrm{Cr}^{6+}$ production.
Therefore, it can be seen from the data of $\mathrm{Cr}^{6+}$ that CSP-B increased from $2 \%$ to $4 \%$, but the corresponding stabilization efficiency of $\mathrm{Cr}^{6+}$ increased slightly, and after the addition of CSP-B increased to $5 \%, \mathrm{Cr}^{6+}$ stabilized significant decrease in efficiency. Except for $\mathrm{Cr}$ and $\mathrm{Cr}^{6+}$, the stabilization of $\mathrm{Cu}, \mathrm{Zn}, \mathrm{Pb}, \mathrm{Ni}$ increased with the increase of the amount of CSP-B added, especially when the CSP-B addition was increased from $2 \%$ to $3 \%$, the efficiency improvement was most obvious. For example, the stabilization efficiency of $\mathrm{Cu}$ was about $99 \%$ when the addition of CSP-B was $3 \%$, and the stabilization efficiency of it was about $99.1 \%$ when the 
addition of CSP-B was $6 \%$. In addition, it can be seen from the Fig. 2. that when the dosage of CSP-B was about $5 \%$, the stabilization efficiency of $\mathrm{Cu}, \mathrm{Zn}, \mathrm{Pb}$, and $\mathrm{Ni}$ has basically reached an ideal level.

In the term of group CSP-P (Fig. 2(g). Fig. 2(i).), it can be seen that the addition of CSP-P contributes to the increase in the stabilization efficiency of $\mathrm{HMs}$. Comparing CSP-P and CSP-B, it can be found that the stabilization effect of CSP-P on $\mathrm{Cr}$ and $\mathrm{Cr}^{6+}$ was significantly better, and the advantage of CSP-B was reflected in the stabilization effect on $\mathrm{Cu}, \mathrm{Zn}, \mathrm{Pb}, \mathrm{Ni}$.

The curing time had a certain effect on the stabilizing efficiency of HMs in contaminated soil as reflected in Fig. 3(a)., Fig. 3(b). and Fig. 3(c).. For example, for CSP group, the effect of stabilizing HMs in the experimental group of 8 days of curing time was better than that of the experimental group of 6 days and 4 days of curing time as reflected in Fig. 3(a)..

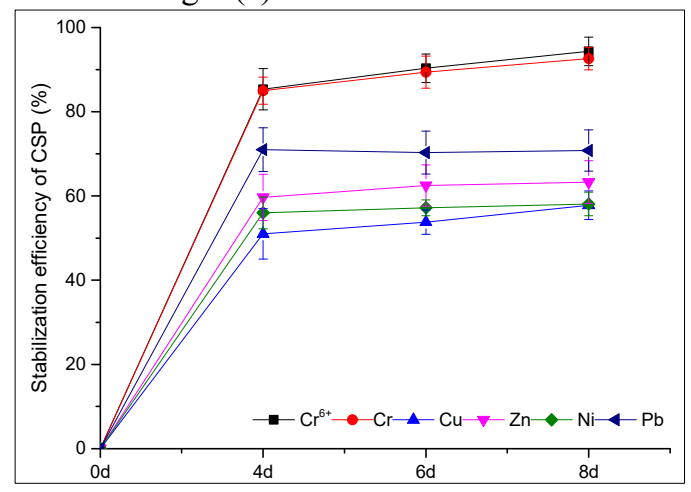

Fig. 3(a). Stabilization results (4\%)

The extension of the curing time can lead to a slight improvement in the final stabilization effect of the contaminated soil, which may be due to the slow and continuous release of chitin in the crab shell. For CSP-B group, after the curing time exceeded 4 days, the effect of stabilizing heavy metals did not increase significantly with the curing time(as reflected in Fig. 3(b).).

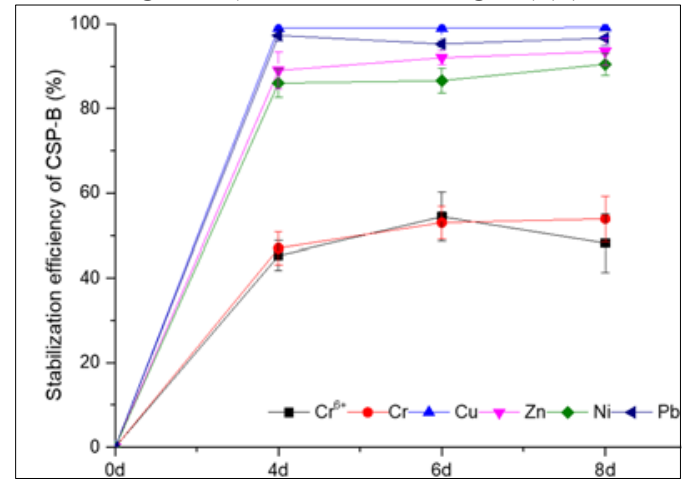

Fig. 3(b). Stabilization results (4\%)

This phenomenon may be because the main mechanism of CSP-B HM stabilization was through the rapid chemical reaction of hydroxide and phosphate with HMs. In term of CSP-P group, after the curing time reaches 4 days, the effect of stabilizing heavy metals no longer increases with the extension of the curing time (as reflected in Fig. 3(c).).

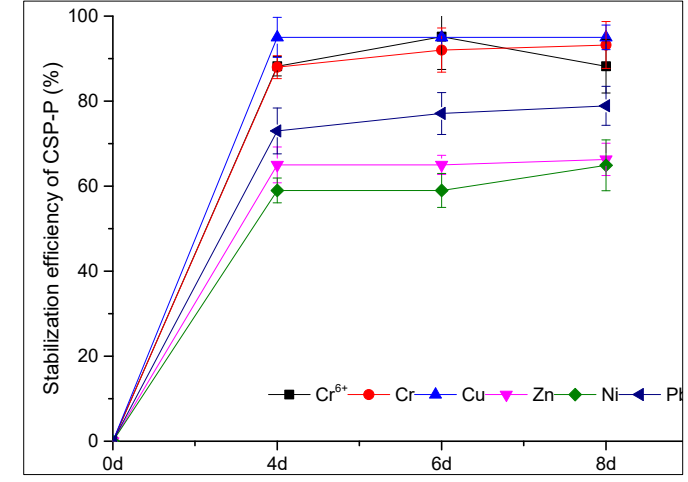

Fig. 3(c). Stabilization results (4\%)

This may be because the heavy metal adsorption of CSP-P was basically completed within the first 4 days of curing.

Since the outstanding stabilizing effects of CSP-P on total $\mathrm{Cr}$ and $\mathrm{Cr}^{6+}$ and the outstanding stabilizing effects of CSP-B on $\mathrm{Cu}, \mathrm{Zn}, \mathrm{Ni}, \mathrm{Pb}$ were observed, a test of stabilizing effects of HMs was conducted after mixing the two substances. The results were shown in Fig. 4..

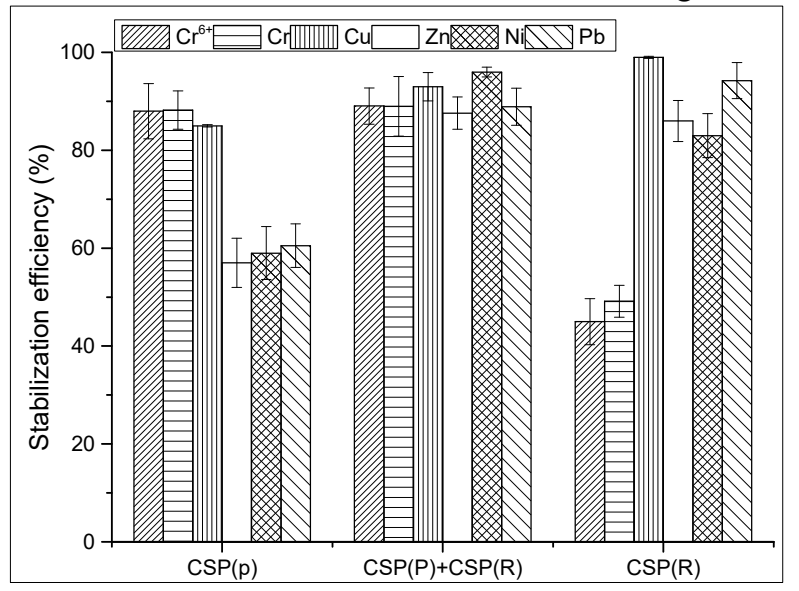

Fig. 4. Stabilization results

Comparing the results of the experimental group of CSP-P, it can be found that the stabilizing effect of $\mathrm{Zn}$, $\mathrm{Ni}$ and $\mathrm{Pb}$ in the mixed agent group has been significantly improved (The stabilization efficiency of $\mathrm{Zn}$ increased from $57.0 \%$ to $86.1 \%$; The stabilization efficiency of $\mathrm{Ni}$ increased from $59.0 \%$ to $96.1 \%$; The stabilization efficiency of $\mathrm{Pb}$ increased from $60.52 \%$ to $88.9 \%$ ). Comparing the results of the experimental group of CSP-B, it can be found that the stabilizing effect of total $\mathrm{Cr}$ and $\mathrm{Cr}^{6+}$ has been also significantly improved in the mixed group(The stabilization efficiency of $89.0 \%$ total $\mathrm{Cr}$ increased from $49.16 \%$ to $89.0 \%$; The stabilization efficiency of $\mathrm{Cr}^{6+}$ increased from $45.0 \%$ to $89.1 \%$;).

\section{Conclusion}

In summary, this study demonstratedhat crab shells, pyrolyzed crab shells, and high-temperature baked crab shells have stabilizing effects on soil heavy metals. Among them, crab shells and pyrolyzed crab shells have 
better stabilizing effects on total $\mathrm{Cr}$ and $\mathrm{Cr}^{6+}$. After high temperature baked, crab shells have better performance on stabilizing $\mathrm{Cu}, \mathrm{Zn}, \mathrm{Pb}$. These results show that when the heavy metal pollution level in the soil reaches the concentration set in this experiment, the curing time can be set to 5-6 days, and the ideal dosage of the agent is $1.5 \%$ of the pyrolysis crab shell and is $1.5 \%$ of baked crab shell. Under this condition, $\mathrm{Cr}, \mathrm{Cr}^{6+}, \mathrm{Cu}, \mathrm{Zn}, \mathrm{Pb}$ and $\mathrm{Ni}$ stabilization efficiency can reach a relatively ideal level.

\section{Acknowledgement}

This work was supported by Zhejiang Science and Technology Research Grant (2018C03028) and (2018A029)

\section{References}

1. J. Kong, Q. Guo, R. Wei, H. Strauss, G. Zhu, S. Li, Z. Song, T. Chen, B. Song, T. Zhou, G. Zheng, Sci. Total Environ. 637-638, 000 (2018)

2. L. Zeng, F. Zhou, X. Zhang, J. Qin, H. Li, Hum. Ecol. Risk Assess. 24, 7 (2018)

3. Y. Chen, P. Wu, Y. Shao, Y. Ying, Sci. Agric. 71, 2 (2014)

4. H. Feng, J. Wu, Y. Guo, J. Dai, Y. Lu, Hum. Ecol. Risk Assess. 23, 3 (2017)

5. K. Zhan, C. Qiang, J. Liu, J. Soils Sediments 18, 5 (2018)

6. Z. Ma, K. Chen, Z. Li, J. Bi, L. Huang, J. Soils Sediments 16, 1 (2016)
7. Y. Li, Y. Wang, X. Gou, Y. Su, G. Wang, J. Environ. Sci. 18, 6 (2006)

8. S. Tokunaga, S. W. Park, M. Ulsan, Environ. Technol. 26, 6 (2005)

9. G. Li, S. Guo, J. Hu, Chem. Eng. J. 286, 000 (2016)

10. Mingcan Cui, Yonghyeon Lee, Jongbok Choi, Jeonggwan Kim, Zhengchang Han, Younggyu Son, Jeehyeong Khim, J. Clean. Prod. 193, 000 (2018)

11. M. Zhang, J. Pu, J. Environ. Sci. 23, 4 (2011)

12. S. Ye, G. Zeng, H. Wu, C. Zhang, J. Dai, J. Liang, J. Yu, X. Ren, H. Y i, M. Cheng, C. Zhang, Crit. Rev. Biotechnol. 37, 8 (2017)

13. Salwinder Singh Dhaliwal, Jaswinder Singh, Parminder Kaur Taneja, Agniva Mandal, Environ. Sci. Pollut. Res. 27, 2 (2020) 